\title{
CONSIDERAÇÕES SOBRE A REPRESENTAÇÃO CARTOGRÁFICA DE RISCOS GEOLÓGICOS
}

\author{
Leandro Eugenio Silva CERRI \\ Vera Cristina Rocha da SILVA \\ Oswaldo AUGUSTO FILHO
}

\section{RESUMO}

Cartas de risco geológico, entendidas como um tipo particular de carta geotécnica, apresentam algumas especificidades. Com base em dados bibliográficos e na análise de exemplos nacionais e internacionais, o presente artigo discute os aspectos referentes às escalas das cartas de risco geológico, os principais elementos cartografados e as técnicas usuais empregadas, além das questões inerentes à durabilidade e ao custo de impressão. Também são apresentadas opiniões quanto à utilização de técnicas computacionais.

\section{ABSTRACT}

Geological hazard maps can be viewed as a particular type of engineering geological map which presents some specific concerns.

This paper discusses some aspects related to the scale, the major elements to be represented and the methods and techniques commonly used for the representation of geological hazard maps. This theme is analysed on the basis of some examples of national and international geological hazard maps.

\section{INTRODUÇÃO}

No Brasil, a cartografia geotécnica como instrumento de apoio ao planejamento do uso do solo ganhou grande impulso no final dos anos 80 , com uma crescente demanda por novas cartas. As cartas geotécnicas podem receber diferentes denominações de acordo com a metodologia empregada e os objetivos pretendidos.

BITAR et al. (1992) apresentam a seguinte classificação: cartas geotécnicas convencionais (quando mostram a distribuição geográfica das características dos terrenos, a partir de atributos do meio físico e de determinados parâmetros geológico-geotécnicos, muitas vezes sem considerar as interações existentes entre o meio físico e as diferentes formas de uso do solo); cartas geotécnicas dirigidas (quando, a partir da identificação de problemas de natureza geológico-geotécnica decorrentes do uso do solo, expõem as limitações e potencialidades dos terrenos, estabelecem alternativas de solução destes problemas e apontam as diretrizes para o adensamento e a expansão da ocupação ante uma ou mais formas de uso do solo); cartas de suscetibilidade (quando indicam a potencialidade de ocorrência de processos geológicos naturais e induzidos em áreas de interesse ao uso do solo, expressando a suscetibilidade segundo classes de probabilidade de ocorrência); cartas de risco geológico (quando prepondera a avaliação de dano potencial à ocupação, expresso segundo diferentes graus de risco, resultantes da conjugação da probabilidade de ocorrência de manifestações geológicas naturais ou induzidas e das consequiências sociais e econômicas decorrentes).

Vários autores consideram as cartas de risco geológico como um tipo de carta geotécnica. Entretanto, há particularidades inerentes à representação cartográfica dos riscos geológicos, algumas das quais discutidas neste artigo. A análise do quadro 1 permite comparar aspectos abordados na elaboração de diferentes cartas de risco geológico, a seguir analisados.

\section{CARTOGRAFIA DE RISCOS GEOLÓGICOS}

ZUQUETTE et al. (1991) descrevem que os documentos gráficos mais conhecidos sobre riscos geológicos são as cartas ZERMOS - 
Zonas Expostas aos Riscos de Movimentos do Solo (França); as cartas de inundações e de potencial aos sismos (EUA, Países do Leste Europeu); as cartas de movimentos de terrenos (Itália); e as cartas de vulnerabilidade à poluição (EUA, Canadá, França). Relatam que, no Brasil, a maior parte das cartas de risco geológico tratam de movimentos de materiais em regiões serranas.

Segundo CERRI et al., (1990), a identificação dos riscos geológicos se dá através de zoneamentos (delimitação das regiões onde as manifestações geológicas podem causar dano) ou de cadastramentos (riscos identificados em maior detalhe, moradia a moradia, em áreas urbanas; ou trecho a trecho, em obras lineares e drenagens).

A definição da escala de representação cartográfica de riscos geológicos é função direta dos objetivos do trabalho. O Office of the United Nations Disaster Relief Co-OrdinatorUNDRO (1978) adota a escala nacional (1:1.000.000 a 1:250.000) para o planejamento do uso do solo a longo prazo; escala regional (1:125.000 a $1: 62.500)$ para o planejamento regional; escala de detalhe $(1: 24.000$ a 1:12.000) para o planejamento urbano e para a análise de vulnerabilidade; e escala de projeto (1:12.000 a $1: 200)$ para um detalhado planejamento do uso do solo e para a normalização das construções.

No Brasil, as cartas de risco geológico têm escalas de 1:50.000 a 1:250 (BITAR et al., 1992; TAKIYA et al., 1992; MACEDO, 1992).

Em geral, as cartas de risco geológico devem apresentar uma hierarquização das situações de risco identificadas, comumente expressa segundo diferentes graus de riscos, visando indicar as áreas mais críticas. Não há uma padronização em relação à representação dos graus de risco, sendo mais comum o emprego das cores verde, amarela e vermelha (esta última para graus mais elevados); de índices numéricos (com índices maiores correspondendo a graus mais elevados) e de texturas (mais densas quanto mais elevado o grau de risco).

Com o objetivo de elaborar cartas mais completas, além dos graus de risco, podem ser cartografados os diferentes processos geológicos. Exemplos dessa técnica podem ser observados no trabalho de OLIVIER \& RENET (1976), onde os processos geológicos também são representados e aparecem diferenciados em antigos, atuais e potenciais.

Já as cartas de risco geológico elaboradas no Brasil geralmente não contêm a representação dos processos considerados no estudo.
Habitualmente, os riscos geológicos identificados são cartografados sobre plantas topográficas, porém nem sempre esta base é a mais indicada. Para zoneamentos de risco em escalas pequenas ou médias, a planta topográfica serve de modo eficiente como base, mas para escalas grandes (especialmente nos cadastramentos de risco) torna-se necessária a utilização de bases com a representação da infra-estrutura local ou, então, de plantas cadastrais atualizadas.

Para fazer frente à carência de bases cartográficas adequadas, BITAR et al. (1992) relatam a utilização de fotografias aéreas de baixa altitude, sobre as quais são assinalados os graus de risco identificados. Afirmam, também, que a carta de risco geológico pode ser um produto cartográfico de validade relativamente curta, a menos que se efetue uma permanente atualização do comportamento dos processos geológicos envolvidos e da dinâmica da ocupação.

\section{UTILIZAÇÃO DE TÉCNICAS COMPUTACIONAIS}

O desenvolvimento da informática e a facilidade de obtenção de equipamentos e de softwares têm favorecido a utilização desse ferramental na cartografia geotécnica, inclusive na elaboração de cartas de risco geológico. Entre as diferentes técnicas disponíveis, destaca-se o Sistema de Informações Geográficas-SIG, que permite o armazenamento, tratamento e análise de diferentes tipos de dados ambientais de determinada área geográfica (sejam de natureza gráfica ou alfanumérica), além de sua representação espacial.

Os SIGs podem ser utilizados para a elaboração das próprias cartas, ou ainda como instrumentos para gerenciamento desses riscos, onde o produto cartográfico corresponde a um dos módulos do sistema, permitindo o seu cruzamento com outras informações (acidentes registrados, número de moradias e de pessoas em risco, medidas estruturais e não estruturais implantadas, condições de acesso...).

CARRARA et al. (1978), apud HANSEN (1984), apresentam uma carta de risco de escorregamentos elaborada com a utilização de um SIG com uma extensa base de dados, englobando: inventário de escorregamentos, levantamentos de campo, fotointerpretação, análise e revisão de mapas geológicos, geomorfológicos e hidrológicos.

A nível nacional, são poucos os exemplos de utilização de SIGs para o gerenciamento de riscos geológicos e para o planejamento do uso do solo. AMARAL et al. (1993) apresentam o 
desenvolvimento de um SIG aplicado ao gerenciamento de áreas de risco de escorregamento no Rio de Janeiro (RJ), que envolve três módulos principais: mapa de risco de escorregamentos, banco de dados de obras de contenção de encostas e banco de dados de laudos de vistorias de acidentes. A partir de coordenadas geográficas de algum ponto da cidade do Rio de Janeiro, o usuário tem acesso aos dados de geologia, declividade do terreno, uso do solo, grau de risco, número de acidentes e intervenções públicas realizadas.

\section{CONSIDERAÇÕES FINAIS}

A elaboração de cartas de risco geológico no Brasil é ainda muito recente. No geral, as cartas produzidas no País são de escalas grandes (talvez pela urgente necessidade em reduzir os riscos instalados), abordando principalmente os processos de escorregamento.

Ao contrário da prática usual em cartografia de levantamentos geológicos básicos e até em algumas cartas geotécnicas convencionais, dirigidas ou de suscetibilidade, sugere-se que as cartas de risco geológico sejam elaboradas na mesma escala utilizada nos trabalhos de campo; dessa forma evita-se que dados importantes (detalhes observados em campo) desapareçam na representação cartográfica.

Nos trabalhos sintetizados no QUADRO 1, predominam os zoneamentos de risco, realizados em escalas grandes, até o limite de 1:2.000. Nota-se que, na definição da escala de representação, pode-se adotar uma diferenciação entre produtos que representam risco potencial e risco atual. O risco potencial corresponde à suscetibilidade natural de ocorrência de processos geológicos, podendo ser apresentado em escalas menores, quando destinado ao planejamento da ocupação. Em relação ao risco atual, os melhores resultados aparecem em escalas maiores, podendo-se iniciar os trabalhos em toda a área na escala 1:10.000, por exemplo, com a finalidade de subsidiar ações de planejamento. A partir dos resultados deste levantamento, pode ser elaborada uma carta de detalhe (na escala 1:2.000, ou maior), envolvendo somente as áreas identificadas como mais críticas.

Em conjunto com a questão da durabilidade (devido à necessidade de atualizações), deve ser considerado o custo envolvido para a impressão das cartas de risco geológico. Devem ser evitados produtos de custo elevado, especialmente aqueles que requerem o uso de grande número de cores. Para a atualização das cartas de risco geológico pode-se utilizar de SIGs (ainda com poucos exemplos no Brasil), o que pode inclusive reduzir o custo de impressão.

A utilização dos SIGs na elaboração de cartas de risco geológico em escalas maiores que 1:25.000 demanda custo crescente na implantação do sistema e necessidade de dados de entrada compatíveis com a escala adotada. Tais condições podem representar um grande limitante, já que no Brasil as cartas de risco geológico são geralmente elaboradas em escalas maiores.

Apesar desse aspecto, a utilização dos SIGs para elaboração de cartas de risco geológico deve ser crescente, uma vez que estudos apontam que essa técnica permite a obtenção de produtos no mesmo espaço de tempo que as técnicas manuais, a um custo relativamente menor, reduzindo o trabalho cansativo e a possibilidade de erros humanos (HANSEN, 1984).

\section{REFERÊNCIAS BIBLIOGRÁFICAS}

AMARAL, C. et al. 1993. SIG alternativo aplicado ao gerenciamento de áreas de risco geológico no Rio de Janeiro. In CONGRESSO BRASILEIRO DE GEOLOGIA DE ENGENHARIA, 7ํㅜ Poços de Caldas, MG. Anais, Poços de Caldas, MG. (No prelo.)

AUGUSTO FILHO, O. 1992. Debris Flow risk map of Petrópolis city, Rio de Janeiro State, Brazil. In: SIMPÓSIO LATINO AMERICANO SOBRE RISCO GEOLÓGICO URBANO, 2º Pereira, Colômbia. Anais. Pereira, Colômbia, CARDER/INGEOMINAS/EAFIT/ AGID/IUGS/IAEG/ONAD, v.2 p.1-12.

BITAR, O.Y. et al. 1992. Carta de risco geológico e carta geotécnica: uma diferencia- ção a partir de casos em áreas urbanas no Brasil. In: SIMPÓSIO LATINO-AMERICANO SOBRE RISCO GEOLÓGICO URBANO, 2ำ, Pereira, Colômbia. Anais. Pereira, Colômbia. CARDER/INGEOMINAS/EAFIT/AGID/IUGS/IAEG/ONAD, v. 2 p. $35-41$.

CARVALHO, E.T. 1987. Carta Geotécnica de Ouro Preto. Síntese de Tese, $1^{a}$ edição, São Paulo, ABGE, 51p.

CENDRERO, A. et al. 1987. Metodologia de elaboracion de mapas de riesgos a escala 1:5.000. Actas III Reunion Nacional de Geol. Ambiental y Ordenación del Territorio. Vol. II p. 843-870. Valencia, Spain. 
QUADRO 1 - Cartas de risco (ênfase aos trabalhos realizados pelo IPT)

\begin{tabular}{|c|c|c|c|c|c|c|c|c|}
\hline Trabalho & $\begin{array}{l}\text { Escala } \\
\text { Área } \\
\text { Local }\end{array}$ & Tipo & Processo & $\begin{array}{l}\text { Tipo de } \\
\text { Risco }\end{array}$ & Base & $\begin{array}{l}\text { Simbologia de } \\
\text { Risco }\end{array}$ & $\begin{array}{l}\text { esentação } \\
\text { Processos }\end{array}$ & Técnicas empregadas \\
\hline $\begin{array}{l}\text { Olivier \& } \\
\text { Renet } \\
(1976)\end{array}$ & $\begin{array}{l}1: 20000 \\
36 \mathrm{~km}^{2} \\
\text { França }\end{array}$ & Zoneamento & $\begin{array}{l}\text { Escorreg./ } \\
\text { inundações }\end{array}$ & $\begin{array}{l}\text { Atual e } \\
\text { Potencial }\end{array}$ & Topograf. & $\begin{array}{l}\text { Cores } \\
\text { semafórica }\end{array}$ & $\begin{array}{l}\text { Símbolos } \\
\text { gráficos }\end{array}$ & $\begin{array}{l}\text { Cartografia manual } \\
\text { sobreposição de mapas } \\
\text { fatores condicionantes }\end{array}$ \\
\hline IPT(1984a) & $\begin{array}{l}1: 2000000 \\
885000 \mathrm{~km}^{2} \\
\text { Sudeste } \\
\text { de SP }\end{array}$ & Zoneamento & Sismos & Potencial & Topograf. & $\begin{array}{l}\text { Hachuras } \\
\text { Letras: } \\
\text { A, B, C-Risco } \\
\text { crescente }\end{array}$ & & $\begin{array}{l}\text { Cartografia manual } \\
\text { sobreposição de mapas } \\
\text { fatores condicionantes } \\
\text { análise histórica }\end{array}$ \\
\hline IPT (1984b) & $\begin{array}{l}1: 5000 \\
1: 2000 \\
\text { Cubatão } \\
\text { SP }\end{array}$ & $\begin{array}{l}\text { Zoneamento } \\
\text { cadastra- } \\
\text { mento }\end{array}$ & Escorreg. & $\begin{array}{l}\text { Atual e } \\
\text { potencial }\end{array}$ & $\begin{array}{l}\text { Topograf. } \\
\text { cadastral } \\
\text { fotos }\end{array}$ & $\begin{array}{l}\text { Números: } \\
\text { I,IV - Risco } \\
\text { crescente }\end{array}$ & $\begin{array}{l}\text { Símbolos } \\
\text { gráficos }\end{array}$ & $\begin{array}{l}\text { Cartografia manual } \\
\text { Sobreposição de mapas } \\
\text { Fatores condicionantes }\end{array}$ \\
\hline IPT (1986) & $\begin{array}{l}1: 2000 \\
0,32 \mathrm{~km}^{2} \\
\text { Cajamar } \\
\text { SP }\end{array}$ & Zoneamento & $\begin{array}{l}\text { Subsidên- } \\
\text { cias e } \\
\text { colapsos }\end{array}$ & Atual & $\begin{array}{l}\text { Topograf. } \\
\text { cadastral }\end{array}$ & $\begin{array}{l}\text { Números } \\
\text { 1,2,3-Risco } \\
\text { crescente }\end{array}$ & & $\begin{array}{l}\text { Cartografia manual } \\
\text { invest. subsuperf. }\end{array}$ \\
\hline $\begin{array}{l}\text { Carvalho } \\
\text { (1987) }\end{array}$ & $\begin{array}{l}1: 2000 \\
8,5 \mathrm{~km}^{2} \\
\text { Ouro } \\
\text { Preto } \\
\text { MG }\end{array}$ & Zoneamento & Escorreg. & Atual & $\begin{array}{l}\text { Topograf. } \\
\text { Cadastral }\end{array}$ & $\begin{array}{l}\text { "Área de } \\
\text { Risco" }\end{array}$ & & $\begin{array}{l}\text { Cartografia manual } \\
\text { Sobreposição de Mapas }\end{array}$ \\
\hline $\begin{array}{l}\text { Cendrero } \\
\text { et al. } \\
(1987)\end{array}$ & $\begin{array}{l}\text { 1:5000 } \\
\text { Espanha }\end{array}$ & Zoneamento & $\begin{array}{l}\text { Escorreg. } \\
\text { Inundações } \\
\text { Colapsos } \\
\text { Erosão } \\
\text { Eólica e } \\
\text { Costeira }\end{array}$ & $\begin{array}{l}\text { Atual e } \\
\text { Potencial }\end{array}$ & Topograf. & $\begin{array}{l}\text { Números: } \\
\text { 1,2,3-Risco } \\
\text { Decrescente } \\
\text { Letras: } \\
\text { A-Alto } \\
\text { M-Médio } \\
\text { B-Baixo } \\
\text { Texturas }\end{array}$ & $\begin{array}{l}\text { Símbolos } \\
\text { Gráficos } \\
\text { Letras }\end{array}$ & $\begin{array}{l}\text { Cartografia Manual } \\
\text { Sobreposição de Mapas } \\
\text { Fatores Condicionantes }\end{array}$ \\
\hline IPT (1988) & $\begin{array}{l}\text { 1:2000 } \\
0,07 \mathrm{~km}^{2} \\
\text { Guaratin- } \\
\text { guetá } \\
\text { SP }\end{array}$ & Zoneamento & Escorreg. & Atual & $\begin{array}{l}\text { Topograf. } \\
\text { Cadastral } \\
\text { Fotos } \\
\text { Aéreas }\end{array}$ & $\begin{array}{l}\text { "Área de } \\
\text { Risco" }\end{array}$ & & $\begin{array}{l}\text { Cartografia Manual } \\
\text { Fatores Condicionantes }\end{array}$ \\
\hline IPT (1990a) & $\begin{array}{l}1: 500 \\
0,07 \mathrm{~km}^{2} \\
\text { Guaratin- } \\
\text { guetá } \\
\text { SP }\end{array}$ & Cadastramento & Escorreg. & Atual & Cadastral & $\begin{array}{l}\text { Números: } \\
\text { I, II-Risco } \\
\text { Decrescente }\end{array}$ & $\begin{array}{l}\text { Símbolos } \\
\text { Gráficos }\end{array}$ & $\begin{array}{l}\text { Cartografia Manual } \\
\text { Fatores Condicionantes }\end{array}$ \\
\hline IPT(1990b) & $\begin{array}{l}1: 5000 \\
1,76 \mathrm{~km}^{2} \\
\text { Carapi- } \\
\text { cuiba } \\
\text { SP }\end{array}$ & Zoneamento & $\begin{array}{l}\text { Escorreg. } \\
\text { Marginais } \\
\text { (Lago) }\end{array}$ & Atual & $\begin{array}{l}\text { Topograf. } \\
\text { Batimetr. }\end{array}$ & $\begin{array}{l}\text { Números: } \\
\text { I, III-Risco } \\
\text { Crescente } \\
\text { Texturas }\end{array}$ & & $\begin{array}{c}\text { Cartografia Manual } \\
\text { Fatores Condicionantes } \\
\text { Modelamento (NA vs } \\
\text { FS) }\end{array}$ \\
\hline IPT $(1990 \mathrm{c})$ & $\begin{array}{l}\text { 1:2000 } \\
\text { 128 Fave- } \\
\text { las-SP } \\
\text { SP }\end{array}$ & Zoneamento & $\begin{array}{l}\text { Escorreg. } \\
\text { Solapamen- } \\
\text { to } \\
\text { Inundação }\end{array}$ & Atual & $\begin{array}{l}\text { Topograf. } \\
\text { fotos } \\
\text { Aéreas } \\
\text { helicop. }\end{array}$ & $\begin{array}{l}\text { Números: } \\
\text { I, II - Risco } \\
\text { decrescente } \\
\text { letras: SR } \\
\text { sem risco }\end{array}$ & Letras: & $\begin{array}{l}\text { Cartografia manual } \\
\text { Fatores condicionantes }\end{array}$ \\
\hline IPT (1991) & $\begin{array}{l}1: 10000 \\
0,31 \mathrm{~km}^{2} \\
\text { SP-SP }\end{array}$ & Zoneamento & Escorreg & Atual & Topograf. & $\begin{array}{l}\text { Números: } \\
\text { 1,2-Risco } \\
\text { decrescente } \\
\text { Letra: SR } \\
\text { sem risco }\end{array}$ & & $\begin{array}{l}\text { Cartografia manual } \\
\text { Fatores condicionantes }\end{array}$ \\
\hline $\begin{array}{l}\text { Augusto } \mathrm{F}^{\circ} \\
\text { (1992) }\end{array}$ & $\begin{array}{l}1: 25000 \\
18000 \mathrm{~km}^{2} \\
\text { Petrópo- } \\
\text { lis-RJ }\end{array}$ & Zoneamento & $\begin{array}{l}\text { Corrida } \\
\text { de massa }\end{array}$ & Atual & Topograf. & $\begin{array}{l}\text { Números } \\
\text { I, IV - risco } \\
\text { crescente }\end{array}$ & $\begin{array}{l}\text { Símbolos } \\
\text { gráficos }\end{array}$ & $\begin{array}{l}\text { Cartografia manual } \\
\text { fatores condicionantes }\end{array}$ \\
\hline IPT (1992) & $\begin{array}{l}\text { 1:2000 } \\
\text { São Se- } \\
\text { bastião } \\
\text { SP }\end{array}$ & Zoneamento & Escorreg. & Atual & $\begin{array}{l}\text { Topograf. } \\
\text { Fotos } \\
\text { áereas } \\
\text { Helicop. }\end{array}$ & $\begin{array}{l}\text { Números: } \\
\text { 1,2-Risco } \\
\text { decrescente } \\
\text { Letras: SR } \\
\text { Sem risco } \\
\end{array}$ & & $\begin{array}{l}\text { Cartografia manual } \\
\text { Fatores condicionantes }\end{array}$ \\
\hline $\begin{array}{l}\text { IPT (1993) } \\
\text { Regionais }\end{array}$ & $\begin{array}{l}\text { 1:10000 } \\
336 \mathrm{Km}^{2} \\
\text { Ilhabela } \\
\text { SP }\end{array}$ & $\begin{array}{l}\text { Escorreg. } \\
\text { Zoneamento }\end{array}$ & $\begin{array}{l}\text { Corrida } \\
\text { de massa } \\
\text { Inundação }\end{array}$ & $\begin{array}{l}\text { Atual } \\
\text { potencial }\end{array}$ & Topograf. & $\begin{array}{l}\text { Números: } \\
\text { 1-3, Risco } \\
\text { Crescente } \\
\text { Letras: } \\
\text { R-Atual } \\
\text { r-Potencial }\end{array}$ & $\begin{array}{l}\text { Letras } \\
\text { Hachuras }\end{array}$ & $\begin{array}{l}\text { Cartografia manual } \\
\text { Fatores condicionantes } \\
\text { Retroanálises }\end{array}$ \\
\hline
\end{tabular}


CERRI, L.E.S. et al. 1990. Risco geológico: uma nova área de atuação da geologia de engenharia no Brasil. In: CONGRESSO BRASILEIRO DE GEOLOGIA DE ENGENHARIA, 6ํㅜㄴ Salvador, BA. ABGE. Anais, Salvador, BA. v.1 p. 319325.

HANSEN, A. 1984. Landslide hazard analysis. In: Slope Instability. Edited by D. Brunsden and D.B. Prior, John Wiley \& Sons Ltd. p. 523-603.

IPT - INSTITUTO DE PESQUISAS TECNOLÓGICAS DO ESTADO DE SÃO PAULO, 1984a. Mapa de risco sísmico do Sudeste Brasileiro. Publicação IPT $\mathrm{n}^{\circ}$ 1563 (Monografia). 48 p.

1984b. Levantamento geológicogeotécnico das áreas de encostas do Município de Cubatão - SP: diretrizes de obras para consolidação dos assentamentos habitacionais. (carta geotécnica). São Paulo. (IPT, Relatório nº 20 481)

1986. Avaliação da Subsidência e Colapso nos Bairros Lavrinhas e Vila Branca, Cajamar, SP. Zoneamento de Risco. São Paulo. (IPT, Relatório no 24 671.)

1988. Parecer técnico na área dos bairros de Pedreira e Alto das Almas, Guaratinguetá, SP. Zoneamento de risco. São Paulo. (IPT, Relatório de Visita Técnica.)

1990. Cadastramento de situações de risco iminente nos bairros de Pedreira e Alto das Almas, Guaratinguetá, SP. São Paulo. (IPT, Relatório nº 27 910.)

1990b. Avaliação de riscos à ocupação nos entornos de lago de extração de areia no Município de Carapicuíba, SP. São Paulo. (IPT, Relatório n ${ }^{\circ} 28$ 255.)

1990c. Análise de risco em favelas críticas do município de São Paulo Coordenação Técnica. São Paulo. (IPT, Relatório $n^{\circ} 28$ 057.)

1991. Análise de situações de risco geológico-geotécnico e elaboração de medidas emergenciais para atenuação de risco na área da Pedreira do Itatinga, SP. São Paulo. (IPT, Relatório nº 29330. .)

1992. Análise e zoneamento de risco e movimentos de massa no bairro de Topolândia, São Sebastião, SP. São Paulo. (IPT, Relatório nº 30 154.)

1993. Plano de redução e prevenção de riscos associados a movimentos de massa e inundações/enchentes para o Município de Ilhabela, SP. São Paulo. (IPT, Relatório $n^{\circ} 31355$. )

MACEDO, E.S. 1992. Zoneamento e cadastramento de risco a escorregamentos em bairro do município de Guaratinguetá, Estado de São Paulo, Brasil. In: SIMPÓSIO LATINO-AMERICANO SOBRE RISCO GEOLÓGICO URBANO, 2ํㅡ. Pereira, Colômbia. Anais. Pereira, Colômbia. CARDERINGEOMINAS/EAFIT/AGID/IUGS/IAEG/ONAD. V. 1p. 199-205.

OFFICE OF THE UNITED NATION DISASTERS RELIEF CO-ORDINATORUNDRO 1978. Disaster prevention and mitigation: a compendium of current knowledge. New York. v. 5: Land use aspects.

OLIVIER, G. \& RENET, P.J. 1976. Essai de Cartographie des risques liés à des mouvements de terrain dans la région de Saint-Martin-de-Belleville, Savoie, France. Bulletin de liasion des Laboratoires des Ponts et Chaussées. Paris. v. 2 Stabilité des talus, I - Versants Naturels p. 40-55.

TAKIYA, H. et al. 1992. Análise de situações de risco geológico-geotécnico em áreas de precária ocupação urbana na região de Campo Limpo, Município de São Paulo SP. In: CONGRESSO BRASILEIRO DE GEOLOGIA, 37ํㅗㅇ São Paulo - SP. Anais. SBG. v. 1. 124-125.

ZUQUETTE. L. V. et al. 1991. Carta de risco da região de Ribeirão Preto (SP); escala 1:50.000. In: SIMPÓSIO DE GEOLOGIA DO SUDESTE, 2ํㅡㄴ, São Paulo - SP. São Paulo, SP. Atas. SBG. p. 361-365. 